\title{
Effect of Tooth Surface Modification on Dynamic Transmission Efficiency of Double Helical Gear Trains
}

\author{
Feng Wang \\ The State Key Laboratory of Mechanical Transmissions, Chongqing University, Chongqing 400044, China. \\ Automotive Engineering Research Institute, Jiangsu University, Zhenjiang 212013, China. \\ E-mail: bewater@163.com
}

Xing Xu and Jiaqi Xia

Automotive Engineering Research Institute, Jiangsu University, Zhenjiang 212013, China.

\author{
Hongbo Que \\ CRCC Qishuyan Institute Co., Ltd., Changzhou 213011, China.
}

(Received 31 March 2021; accepted 22 September 2021)

\begin{abstract}
To analyze the influence mechanism of vibration loads on dynamic transmission efficiency (DTEF) of double helical gear trains (DHGT), a calculation method of DTEF which takes into consideration the real-time dynamic loads is proposed from the perspective of improving both efficiency and precision. The average DTEF is taken as the dynamic objective function of optimization for three-dimensional modification technology of tooth surface. An engineering example is given in this form of a numerical simulation, which proves that the average DTEF with the consideration of dynamic loads is obviously lower than the static transmission efficiency (STEF), especially for the resonance speed region. The results also show that the DTEF after 3-D modification is significantly improved, owing to the improvement of the meshing state of the tooth surface. The comparison of DTEF with different loads and speeds via simulation and experiment further demonstrates the credibility of the theoretical perspectives. This study gives the explanation on the importance of DTEF in the determination of driveline parameters and estimation of transmission quality of DHGT. The developed method for DTEF analysis is practical in engineering and establishes a reliable foundation for further research on design of high-quality double helical gear trains.
\end{abstract}

\section{INTRODUCTION}

Double helical gear trains are characterized by a large torque transmission capacity, superior transmission smoothness, and low axial force, which accounts for their large scale applications in ships and other heavy machinery. ${ }^{1-4}$ With the development of Pratt \& Whitney's geared turbofan engine, double helical gear trains have also become the key transmission parts of an aircraft engine, which work under variable speed processes. $^{5-9}$

Owing to the relatively high mesh ratio and high sensitivity to error, the transfer efficiency of apowertrain is a crucial factor that influences the quality of double helical gear trains, especially in the high speed and heavy-load driveline system of an aircraft engine. Power loss of double helical gear trains is caused by various factors, such as mechanical friction of meshing teeth, supporting bearings, shaft parts, and resistance while stirring the lubricating oil, etc. One of the most important steps during the design of a double helical gear trains is estimation of transmission efficiency, therefore the research on the mechanism of power loss in double helical gear trains is critical for the process of design, optimization, and operation. Extensive research on the static loss mechanism of gear transmission has been carried out by scholars worldwide. Kolivand ${ }^{10}$ proposed a mathematical efficiency model incorporating hybrid elasto- hydrodynamic lubrication (EHL) and an efficiency model for calculating the friction power loss based on the tooth surface traction model, the efficiency models were also applied with different misalignments to examine the influences of critical operating conditions and design parameters on the meshing power loss of mechanical gears. Furthermore, Li and Kahraman $^{11,12}$ offered a transient contact model of cylindrical gear tooth surface, which took into consideration a series of timevarying incentive factors, including the curvature radius, external torque and slip-roll ratio of contact surface. Recently some simulations based on computational fluid dynamics have been proposed. ${ }^{13-15}$ A considerable time-saving numerical methods based on some specific techniques for mesh processing are also widely employed to improve the calculation efficiency of computational fluid dynamics simulations. ${ }^{16}$

With the increase in operating speed of modern transmission machinery, the influence of dynamic loads on transmission efficiency cannot be ignored. The transmission efficiency with dynamic load is defined as DTEF; and some previous work on DTEF has been introduced in literature. Chen and Liang ${ }^{17}$ put forward the analytical expressions of a 2-DOF transmission efficiency based on a methodology of virtual power, which was associated with the varying loads. In order to make an indepth analysis of DTEF of a vehicle powertrain, a calculation 
method for power losses during the process of gear transmission, were deduced from the EHL theory, and the validity of the DTEF model was proved by comparisons with experimental data. ${ }^{18-20}$ However, most of these works assume a constant vibration load (i.e., dynamic load factor and average dynamic load), the dynamic relationship between the complex variable load and transmission efficiency is overlooked. Thusly the inclusion of real-time dynamic loads is essential to improve the accuracy of the DTEF calculation.

In order to meet the requirements of high transmission efficiency, a variety of approaches and technologies have been used to improve the efficiency of gear transmission. Petrescu ${ }^{21}$ analyzed the influence of a few parameters on gear efficiency (including the teeth number of the active gear, the teeth number of the passive gear, pressure angle of divided circle, the helix angle), and these parameters were optimized to improve efficiency. Tůma ${ }^{22}$ pointed out that the smallest possible peakto-peak value of the transmission error could reduce the internal excitation source of the vibration in gear train and improve the contact state of the tooth surface, which eventually brought about higher meshing smoothness and transmission efficiency of the gear train. Alberto ${ }^{23,24}$ focused specifically on the influences of tooth profile modification on load distribution. The results showed that the modification of gear tooth tip brought about a reduction in length of the mesh line and an increase in transmission efficiency. In previous study of Concli, ${ }^{25}$ the load-dependent loss was reduced by approximately $35 \%$ and the total efficiency at nominal speed and torque was increased by $1 \%$, by reducing the module and changing the planet carrier. The modification of gear surface, especially the 3-D modifications, is the principal method to improve meshing performance and transmission efficiency. ${ }^{26-28}$

With the increasing demand for low vibration and high transmission efficiency of double helical gear trains, it is worth considering comprehensive effects so that time-varying mesh stiffness and dynamic meshing torque can be observed simultaneously. The goal of this study is to improve the DTEF of double helical gear trains via 3-D modification of the tooth profile. Additionally, the problem of enhancing DTEF is converted into finding the optimal coefficients of the 3-D modification tooth by a genetic algorithm. In particular, the calculation method of DTEF considering time-varying mesh stiffness and friction torque excitations will fill the research gap compared with previous studies. The main contribution of the proposed dynamic transmission efficiency enhancement method lie in the following three aspects:

1. For double helical gear trains, the time-varying mesh stiffness and friction torque excitations are taken into consideration comprehensively to calculate more accurately the dynamic meshing load.

2. Based on the analysis of the influence of the dynamic meshing load, a novel methodology is proposed for double helical gear trains to obtain the DTEF, which is closer to the practicality.

3. To elevate the DTEF, the methodology for 3-D tooth surface modification is accordingly designed based on these analyses, then the experiments are carried out, including the manufacture of gear sets, closed-power-flow rig tests and data acquisition; the feasibility, effectiveness and advances in practical application are verified.

This paper is organized as follows: The first part aims to review the published papers that dealt with the power loss mechanism of gear transmission system and the corresponding method for optimization. With the purpose of calculating accurately and quickly the DTEF of double helical gear trains under various working conditions introduced in Section 3, the power losses of double helical gear trains, including the friction loss between meshing teeth surfaces and rolling bearing contact surfaces, as well as windage resistance loss, are illustrated in Section 2, the comparison of DTEF with different torques and rotational speeds is also presented in Section 2. In Section 4, to improve the DTEF of double helical gear trains, teeth modification and optimization are carried out. Subsequently, in Section 5, based upon a double helical gear test bench with mechanical closed power flow, the DTEF are carefully measured and used to validate the model. The last part summarizes the principal findings of this research.

\section{TRANSMISSION POWER LOSS MECHANISM OF DHGT}

Gear transmission is the most efficient solution for continuous drive, the efficiency of cylindrical gear transmission is higher than bevel gear, arc tooth gear and other gear systems. ${ }^{29,30}$ The double helical gear trains (DHGT) feature a larger contact surface area compared with spur/helical gear, which makes it difficult to generate the lubricating oil film on gear teeth, therefore, the study of transmission power loss mechanism is of great significance. It is generally believed that the power loss of the enclosed DHGT mainly includes the friction loss of contacting teeth surfaces, friction loss of rolling bearing and windage loss. In this section, the power loss of double helical gear trains considering real-time dynamic loads will be calculated in detail. The primary innovations of transmission power loss mechanism model built in this research can be summarized as follows:

(1) The meshing friction loss of the tooth pair is calculated based on loaded tooth contact analysis (LTCA), in which the geometric meshing characteristics of gear tooth surface is taken into consideration. To obtain a more accurate surface load distribution, the accuracy of meshing friction loss calculation can be elevated accordingly. (2) The dynamic load, which is closer to the practicality and intended to describe the actual real-time meshing force, is introduced for the analysis of meshing friction loss of tooth pair, therefore the calculation accuracy of dynamic meshing power loss can be further improved.

\subsection{Tooth Pair Meshing Friction Loss of DHGT}

The calculation process of LTCA using the double-helical gear pair model is illustrated in Fig. 1. where $I, I I, I I I, I V$ represent the contacting gear teeth at a given instant during the meshing period. The profile of gear teeth shown in Fig. 1 is along the normal direction of the contacting tooth surface. And 
$j q(q=I, I I, I I I, I V)$ denote the meshing point, $i q$ denote the central contacting position along the principal direction of contacting surfaces. The gap vector between all contact pairs in the initial state of contact is represented by $[w]_{k}$.

Under the action of external loads $P_{L}$ and $P_{R}$, the driving gear rotates and makes an angular displacement $Z$, meanwhile, the teeth deformation causes the redistribution of contacting load between contacting teeth. The force equilibrium with plastic deformation is described in Eq. (1).

$$
\begin{gathered}
{[\boldsymbol{p}]_{k}[\boldsymbol{\delta}]_{k}+[\boldsymbol{w}]_{k}=[\boldsymbol{d}]_{k}+[\boldsymbol{Z}], q=I, I I, I I I, I V ;} \\
\left\{\begin{array}{l}
\sum_{j=1}^{n} p_{i \mathrm{I}}+\sum_{j=1}^{n} p_{i I \mathrm{I}}=P_{L} \\
\sum_{i=1}^{n} p_{i I I I}+\sum_{j=1}^{n} p_{i I V}=P_{R} \\
P_{L}+P_{R}=P
\end{array}\right. \\
\left\{\begin{array}{lll}
p_{i q}>0 & \text { when } \quad d_{i q}=0 \\
d_{i q}>0 & \text { when } \quad p_{i q}=0
\end{array}\right.
\end{gathered}
$$

where $[\boldsymbol{p}]_{k}$ denotes the contact loads matrix of teeth surfaces; $[\boldsymbol{d}]_{k}$ denotes the teeth clearance matrix after deformation; $[\boldsymbol{\delta}]_{k}$ denotes the flexibility matrix of teeth pair.

Due to the multi-surface contact and heavy-load operation, the mesh power loss in teeth pairs accounts for a major proportion of transmission power loss. The mesh power loss is primarily associated with the transverse load distribution factor of the gear pair, the relative sliding speed and relative rolling velocity between contacting teeth surfaces. ${ }^{31-34}$

First, mesh power loss along the entire mesh period of every contacting teeth pair should be calculated. There is no absolute smooth gear tooth surface under the conditions of practical application, nor an adequate lubrication, therefore the teeth pairs usually operate under the EHL condition. As illustrated in Fig. 2, the oil film of EHL (point C) and contacting peak of boundary lubrication (point $\mathrm{D}$ ) move simultaneously on meshing tooth surfaces.

In the situation of mixed EHL, the synthetic friction coefficient of contacting surfaces of the meshing gear pair is calculated by Eq. (4).

$$
\mu_{M}=\frac{1-f_{\epsilon}}{\mu_{B}}+f_{\epsilon} \mu_{E}
$$

where $\mu_{M}$ is the equivalent friction coefficient with mixed elastohydrodynamic lubrication; $\mu_{E}$ is the equivalent friction coefficient with elastohydrodynamic lubrication; $\mu_{B}$ is the equivalent friction coefficient with boundary lubrication; $f_{\epsilon}$ represents the percentage that the peak-to-peak contacts take in all teeth surface contacts, and the corresponding calculation is illustrated in Eq. (5).

$$
\left\{\begin{array}{l}
f_{\epsilon}=\frac{1.21 \epsilon^{0.64}}{1+0.37 \epsilon^{1.26}} \\
\epsilon=\frac{H_{\min }}{\sigma} \\
\sigma=\sqrt{\sigma_{p}^{2}+\sigma_{g}^{2}}
\end{array} ;\right.
$$

where $\epsilon$ indicates the film thickness ratio, which is within [1,3] in the condition of mixed elastohydrodynamic lubrication; $\sigma$ indicates the relative roughness of contacting teeth surfaces, and $\sigma_{p}, \sigma_{g}$ denote the roughness of active gear and passive gear; $H_{\min }$ indicates the minimum allowable film thickness in the condition of EHL, the corresponding calculation are elaborated in literature. . $^{35,36}$
In the condition of boundary lubrication, the tooth surface after the running-in process is considered to be in the state of elastic micro peak contact, and the boundary film are not broken. It is also assumed that the friction coefficients of each asperity are the same, and the boundary lubrication friction coefficient $\mu_{B}$ is calculated by Eq. (6).

$$
\mu_{B}=\frac{\sum_{i=1}^{N} \oint_{A_{c i}} \tau_{c i} d A_{c i}}{P_{B}}
$$

where $N$ represents the asperity number of contacting teeth surface; $A_{c i}$ represents the contacting area of asperity $i ; \tau_{i}$ denotes the shear stress of asperity $i ; P_{B}$ denotes the asperity contact pressure. The value of $\mu B$ varies within a narrow range of $0.07-0.15$, which is identified by the experiment. ${ }^{37}$

The equivalent friction coefficient $\mu_{E L}$ under the condition of full-film lubrication can be deduced from the EHL model, as shown in Eq. (7)-(9).

$$
\begin{gathered}
\left\{\begin{array}{l}
\mu_{E}=e^{f k} \cdot\left(P_{h}(t)\right)^{b_{2}} \cdot|S R(t)|^{b_{3}} \cdot\left(v_{e}(t)\right)^{b_{6}} \\
\eta_{M} \cdot(\rho(t))^{b_{8}} \\
f k=b_{9} \cdot e^{S}+b_{4} \cdot \gamma+b_{4} \cdot e^{-\gamma}+b_{1} \\
\gamma=\log _{10}\left(\eta_{M}\right) \cdot|S R(t)| \cdot P_{h}(t)
\end{array}\right. \\
\left\{\begin{array}{l}
\nu_{e}(t)=\left|\nu_{p}(t)+\nu_{g}(t)\right| \\
\nu_{r}(t)=\left|\nu_{p}(t)-\nu_{g}(t)\right|
\end{array}\right. \\
\left\{\begin{array}{l}
S R(t)=\frac{2 \nu_{r}(t)}{\nu_{e}(t)} \\
\rho(t)=\frac{\rho_{p}(t) \cdot \rho_{g}(t)}{\rho_{p}(t)+\rho_{g}(t)}
\end{array}\right.
\end{gathered}
$$

where $v_{e}(t), v_{r}(t)$ are rolling speed and relative sliding speed of contact point, respectively; $v_{p}(t), v_{g}(t)$ are linear velocity of meshing position of driven and driving gear pair; $S R(t)$ denotes the sliding-rolling ratio of the tooth contacting point; $\rho(t)$ denotes the equivalent curvature radius at the teeth contacting point; $\rho_{p}(t), \rho_{g}(t)$ denote the curvature radius of driven gear and driving gear at the contacting point; $P_{h}(t)$ is the Hertzian stress at the tooth contact point; $\eta_{M}$ is the dynamic viscosity of lubricating oil. The coefficients $b_{1}-b_{9}$ are given in Tab. 1 , which is introduced in Ref. ${ }^{38-42}$

The method for the friction coefficient calculation in the condition of a single given point between meshing teeth surfaces is presented above. Whereas for the gear pairs with high contact ratio, as in the case of double helical gears, there are usually more than one pair of teeth mesh at the same time, the engagement mark of a meshing double helical gear pair obtained with LTCA method is illustrated in Fig. 3.

It is observed that there are 16 contact lines in the duration from start to end of entire engagement, and a meshing cycle is formed every five intervals in the LTCA analysis program. Tab. 2 lists the instantaneous contacting teeth pairs in a meshing cycle, $\Delta t$ denotes the meshing period of a mesh cycle.

Consequently, the transverse loading distribution factor of gear pair, the relative rolling and sliding velocity between contacting teeth surfaces are acquired with LTCA method, ${ }^{43}$ and the mesh friction loss of double helical gear trains in the case 


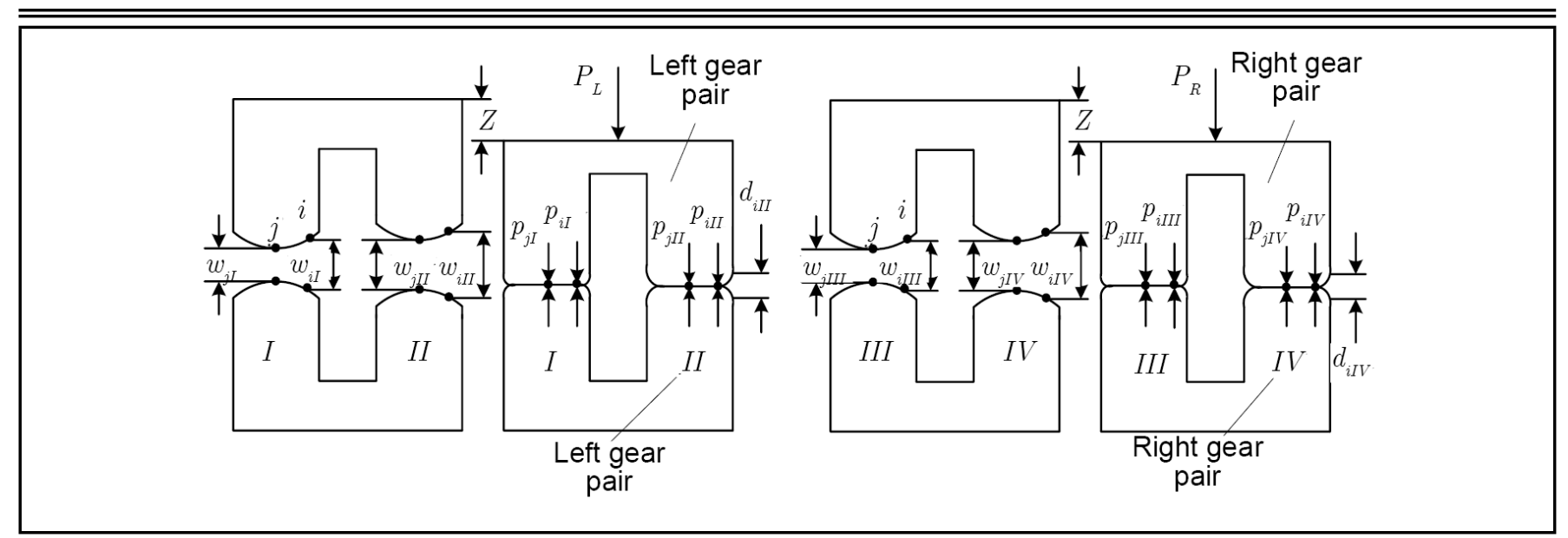

Figure 1. Double helical gear mesh model for LTCA.

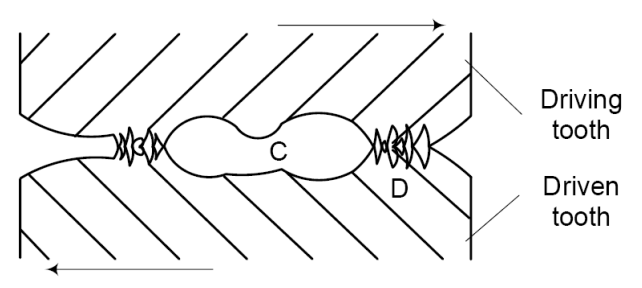

Figure 2. Mixed EHL of meshing gear pair.

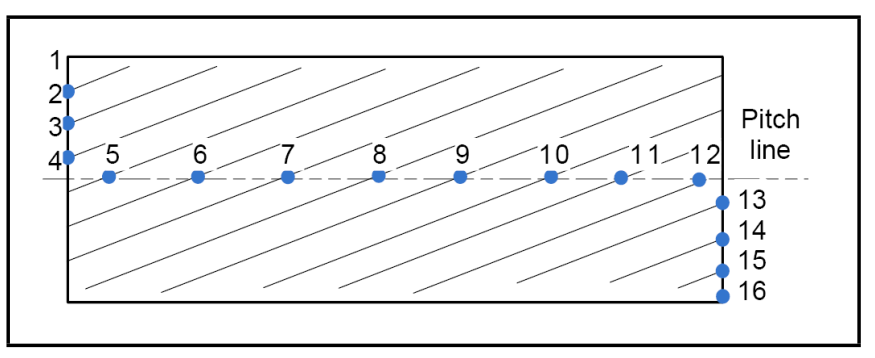

Figure 3. Engagement trajectory of helical gear pair.

of a given static load is deduced from Eq. (1) Eq. (10).

$$
\begin{aligned}
& P_{f k}=\sum_{i=1}^{c e i l\left(\frac{n+1-k}{6}\right)}\left\{\sum _ { j = 1 } ^ { m _ { k + 6 ( i - 1 ) } } \left(\left|V_{k+6(i-1), j}\right| \cdot\right.\right. \\
& \left.\left.F_{n} \lambda_{k+6(i-1), j} \cdot \mu_{k+6(i-1), j}\right)\right\} \ldots \ldots(k=1,2,3,4,5,6) ;
\end{aligned}
$$

where $P_{f k}$ is the mesh friction power loss of teeth surface under a given load $F_{n} ; n$ is the order of contact lines of a single gear tooth engagement; $k$ is the rotating sequence number; ceil is the ceiling function; $m_{k+6(i-1)}$ is the number of scattered mesh points in $k+6(i-1)$ order contact line; $\mu_{k+6(i-1), j}, \lambda_{k+6(i-1), j}, V_{k+6(i-1), j}$ are the comprehensive equivalent friction coefficient, transverse loading distribution factor of gear pair, and the sliding speed at $j$ th mesh point of $k+6(i-1)$ order contact line.

Additionally, there are two conventional methods to calculate the dynamic power loss of meshing teeth pairs in the case of time-varying meshing force. An easy way is just to replace the static torque with the vibration torque at each instance, and the transverse loading distribution factor of gear pair, the relative rolling and sliding velocities between contacting teeth sur-

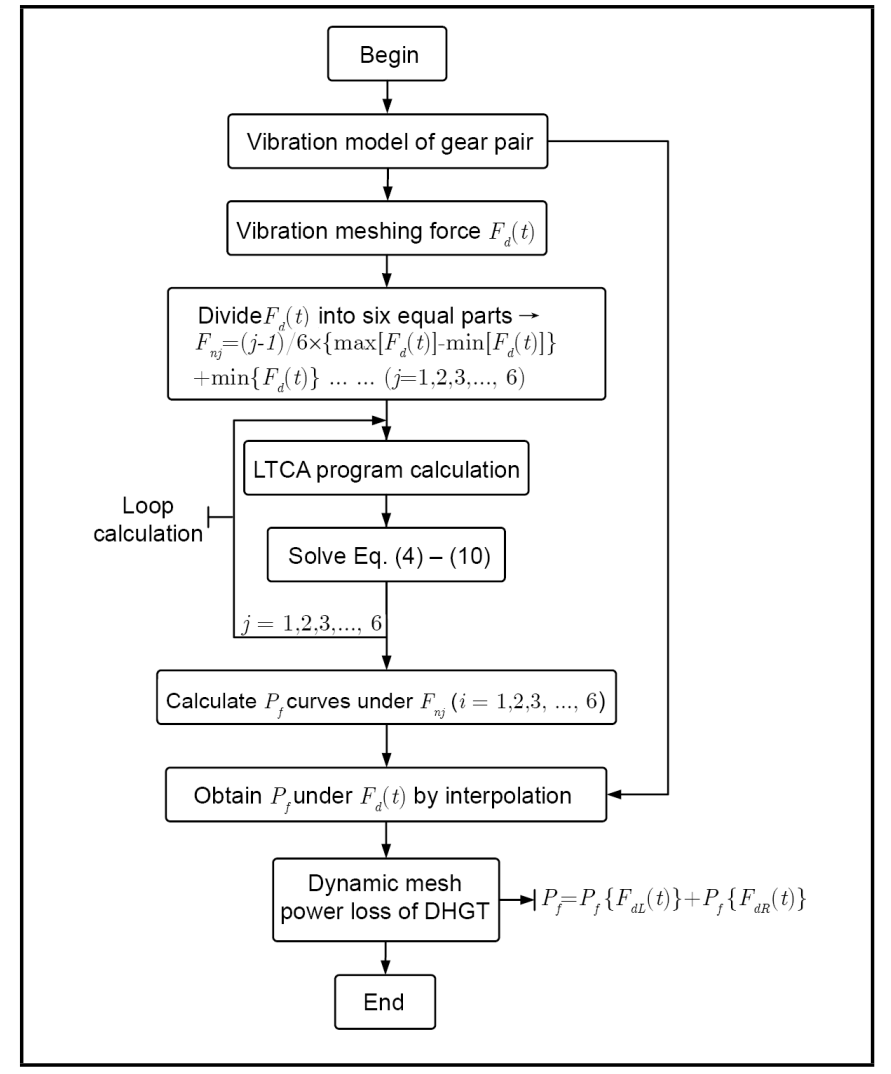

Figure 4. A novel mesh power loss calculation method considering dynamic loads.

faces are kept constant. Another accurate but time-consuming approach is to execute repeatedly the LTCA program and solve Eq. (4)-(10) for every transient vibration load, Fig. 4 illustrates a novel method that integrates the advances of the methods mentioned above to calculate the mesh power loss.

According to the analysis above, to calculate the vibration loads $\left(F_{d L}(t)\right.$ and $\left.F_{d R}(t)\right)$ of double helical gear trains, a dynamic double-helical gear model is initially put forward with the consideration of corner mesh impact force excitation, timevarying mesh stiffness excitation and dynamic friction force excitation of tooth surface. The dynamic double-helical gear model denotes a kinetic system in which the translational and rotational dynamic equations are both employed to describe the motion of system, as illustrated in Fig. 5. It is worth noting that the contacting force of the tooth surface can be decomposed 
Table 1. Value of the parameters $b_{1}-b_{9}$

\begin{tabular}{||c|c|c|c|c|c|c|c|c|c|}
\hline Variable & $b_{1}$ & $b_{2}$ & $b_{3}$ & $b_{4}$ & $b_{5}$ & $b_{6}$ & $b_{7}$ & $b_{8}$ & $b_{9}$ \\
\hline Value & -8.91 & 1.03 & 1.04 & -0.35 & 2.81 & -0.101 & 0.75 & -0.39 & 0.62 \\
\hline
\end{tabular}

Table 2. Instantaneous contact teeth pairs in a meshing cycle.

\begin{tabular}{|c|c|c|c|c|c|c|}
\hline Meshing period & 0 & $1 / 6 \times \Delta t$ & $2 / \times \Delta t$ & $3 / 6 \times \Delta t$ & $4 / 6 \times \Delta t$ & $5 / 6 \times \Delta t$ \\
\hline Number of mesh lines & $1 ? 7 ; 13$ & $2 ; 8 ; 14$ & $3 ; 9 ; 15$ & $4 ; 10 ; 16$ & $5 ; 11$ & $6 ; 12$ \\
\hline
\end{tabular}

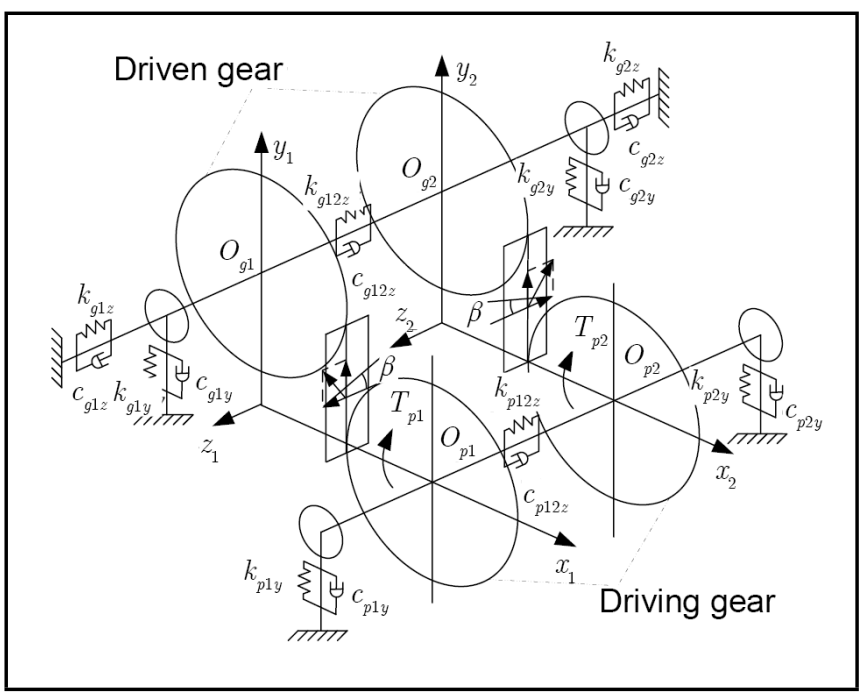

Figure 5. Vibration model of double helical gear pairs.

into two forces in different directions: the direction of meshing line and the direction of gear shaft. The direction of y-axis in this vibration model is defined as the direction of meshing line, and the direction of $\mathrm{z}$-axis is defined as the direction of the gear shaft, therefore, the spring that supports the bearings in the $\mathrm{x}$-axis direction in Fig. 5 is ignored in this practical application.

In accordance with the mutual movement relationship in Fig. 5, the vibration equations of double-helical gear pair are finally given in Eq. (11)-(16).

$$
\left\{\begin{array}{l}
m_{p 1} \ddot{y}_{p 1}+k_{p 1 y} y_{p 1}+c_{p 1 y} \dot{y}_{p 1}=-F_{y 1}+m_{p 1} g \\
m_{g 1} \ddot{y}_{g 1}+k_{g 1 y} y_{g 1}+c_{g 1 y} \dot{y}_{g 1}=F_{y 1}+m_{g 1} g \\
m_{p 2} \ddot{y}_{p 2}+k_{p 2 y} y_{p 2}+c_{p 2 y} \dot{y}_{p 2}=-F_{y 2}+m_{p 2} g \\
m_{g 2} \ddot{y}_{g 2}+k_{g 2 y} y_{g 2}+c_{g 2 y} \dot{y}_{g 2}=F_{y 2}+m_{g 2} g
\end{array}\right.
$$

$$
\left\{\begin{array}{l}
m_{p 1} \ddot{z}_{p 1}+k_{p 12 z}\left(z_{p 1}-z_{p 2}\right)+c_{p 12 z}\left(\dot{z}_{p 1}-\dot{z}_{p 2}\right)=-F_{z 1} \\
m_{g 1} \ddot{z}_{g 1}+k_{g 1 z} z_{g 1}+c_{g 1 z} \dot{z}_{g 1}+k_{g 12 z}\left(z_{g 1}-z_{g 2}\right)+ \\
c_{g 12 z}\left(\dot{z}_{g 1}-\dot{z}_{g 2}\right)=F_{z 1} \\
m_{p 2} \ddot{z}_{p 2}-k_{p 12 z}\left(z_{p 1}-z_{p 2}\right)-c_{p 12 z}\left(\dot{z}_{p 1}-\dot{z}_{p 2}\right)=-F_{z 2} \\
m_{g 2} \ddot{z}_{g 2}+k_{g 2 z} z_{g 2}+c_{g 2 z} \dot{z}_{g 2}-k_{g 12 z}\left(z_{g 1}-z_{g 2}\right)- \\
c_{g 12 z}\left(\dot{z}_{g 1}-\dot{z}_{g 2}\right)=F_{z 2}
\end{array}\right.
$$

$$
\left\{\begin{array}{l}
I_{p 1} \ddot{\theta}_{p 1}=-F_{y 1} \cdot R_{p}+F_{d L} \cdot \chi_{p 1}+T_{p 1}-F_{s 1} \cdot R_{p} \\
I_{g 1} \ddot{\theta}_{g 1}=F_{y 1} \cdot R_{g}-F_{d L} \cdot \chi_{g 1}-T_{g 1}+F_{s 1} \cdot R_{g} \\
I_{p 2} \ddot{\theta}_{p 2}=-F_{y 2} \cdot R_{p}+F_{d R} \cdot \chi_{p 2}+T_{p 2}-F_{s 2} \cdot R_{p} \\
I_{g 2} \ddot{\theta}_{g 2}=F_{y 2} \cdot R_{g}-F_{d R} \cdot \chi_{g 2}-T_{g 2}+F_{s 2} \cdot R_{g}
\end{array}\right.
$$

$$
\begin{aligned}
& \left(F_{d L}=c_{m 1}\left[\cos \beta_{1}\left(R_{p} \dot{\theta}_{p 1}-R_{g} \dot{\theta}_{g 1}+\dot{y}_{p 1}-\dot{y}_{g 1}\right)+\right.\right. \\
& \left.\sin \beta_{1}\left(\dot{z}_{p 1}-\dot{z}_{g 1}\right)\right]+ \\
& k_{m 1}\left[\cos \beta_{1}\left(R_{p} \theta_{p 1}-R_{g} \theta_{g 1}+y_{p 1}-y_{g 1}\right)+\right. \\
& \left.\sin \beta_{1}\left(z_{p 1}-z_{g 1}\right)\right] \\
& F_{d R}=c_{m 2}\left[\cos \beta_{2}\left(R_{p} \dot{\theta}_{p 2}-R_{g} \dot{\theta}_{g 2}+\dot{y}_{p 2}-\dot{y}_{g 2}\right)+\right. \\
& \left.\sin \beta_{2}\left(\dot{z}_{p 2}-\dot{z}_{g 2}\right)\right]+ \\
& k_{m 2}\left[\cos \beta_{2}\left(R_{p} \theta_{p 2}-R_{g} \theta_{g 2}+y_{p 2}-y_{g 2}\right)+\right. \\
& \left.\sin \beta_{2}\left(z_{p 2}-z_{g 2}\right)\right] \\
& \begin{array}{l}
\left\{\begin{array}{l}
F_{y 1}=\cos \beta_{1} F_{d L} \\
F_{z 1}=\sin \beta_{1} F_{d L}
\end{array} ;\right. \\
\left\{\begin{array}{l}
F_{y 2}=\cos \beta_{2} F_{d R} \\
F_{z 2}=\sin \beta_{2} F_{d R}
\end{array} ;\right.
\end{array}
\end{aligned}
$$

where $I_{i j}, m_{i j}(j=1,2 ; i=p, g)$ indicate the moment of inertia and mass of active and passive gears; $R_{p}, R_{g}$ denote the base radii of active and passive gears; $\theta_{i j}$, and $z_{i j}, y_{i j}(j=$ $1,2 ; i=p, g)$ denote the dynamic rotational angles and the vibration displacements of every gear pairs; $F_{d L}, F_{d R}$ denote the vibration mesh forces of right helical mesh teeth pair and left helical mesh teeth pair along the normal direction of meshing tooth surface; $c_{i j z}, c_{i j y}$ and $k_{i j z}, k_{i j y}(j=1,2 ; i=p, g)$ denote the axial and radial supporting damp and stiffness of rolling bearings; $k_{p 12 z}, k_{g 12 z}$, and $c_{p 12 z}, c_{g 12 z}$ indicate the axial supporting stiffness and damping of knife retracting groove; $F_{z 1}, F_{z 2}$, and $F_{y 1}, F_{y 2}$ denote the vibration mesh forces in axial and mesh line directions; $\chi_{p 1}, \chi_{p 2}, \chi_{g 1}, \chi_{g 2}$ indicate the equivalent friction coefficients of driving torque and driven torque; $c_{m 1}, c_{m 2}$ denote the mesh damping of right helical gear teeth pair and left helical gear teeth pair; $F_{s 1}, F_{s 2}$ indicate the corner mesh impact forces in right helical gear teeth pair and left helical gear teeth pair; $k_{m 1}, k_{m 2}$ denote the time-varying mesh stiffness of right helical gear teeth pair and left helical gear teeth pair, which can be obtained by LTCA program, and the calculation methods of meshing stiffness and equivalent meshing damping coefficients are elaborated in; ${ }^{44} \beta_{1}, \beta_{2}$ denote the helix angles of right helical gear teeth pair and left helical gear teeth pair, where $-\beta_{2}=\beta_{1}$.

\subsection{Rolling Bearing Friction Loss of DHGT}

Calculation methods of rolling bearing power loss are complex and diverse, according to reference, ?? the power loss of rolling bearing primarily includes the loss correlated with the load and the loss correlated with viscosity, and the rolling bearing friction loss of double helical gear trains can be obtained by Eq. (17)-(18).

$$
P_{B}=\sum_{i=1}^{n_{b}} \omega_{b}\left(0.0009\left(\frac{F_{S T}}{C_{S}}\right)^{0.55} \cdot F_{\beta} D_{m}+M_{V}\right) ;
$$




$$
M_{V}=\left\{\begin{array}{l}
1.42 \times 10^{-5} f_{0}\left(v \omega_{b}\right)^{2 / 3} D_{m}^{3} C_{1} \quad \text { when } \\
v \cdot \omega_{b}>2000 \\
3.492 \times 10^{-3} f_{0} D_{m}^{3} C_{2} \quad \text { when } \\
v \cdot \omega_{b} \leq 2000
\end{array}\right.
$$

where $n_{b}$ is the number of rolling bearing; $F_{S T}$ is the equivalent static load of bearing; $C_{S}$ is the rating static load of bearing; $F_{\beta}$ is the equivalent normal contacting load considering the bearing cone angle; $D_{m}$ is the bearing diameter; $M_{V}$ is the viscous power loss of rolling bearing; $f_{0}$ is the lubrication coefficient of rolling bearing; $\omega_{b}$ is the relative speed between the inner and outer rings of bearing; $v$ is the kinetic viscosity coefficient of lubricating oil; $C_{1}, C_{2}$ are constants of proportionality, $C_{1}=C_{2}=6894$.

To ensure the accuracy of calculation in the case of vibration loads, according to Fig. 5, the equivalent static loads are replaced by the dynamic loads, as shown in Eq. (19).

$$
\left\{\begin{array}{l}
F_{i j}(t)=k_{i j y} y_{i j} \cdots(i=p, g j=1,2) \\
F_{a}(t)=k_{g 1 z} z_{g 1}+k_{g 2 z} z_{g 2}
\end{array}\right.
$$

\subsection{Windage Loss of DHGT}

The windage loss appears in gearbox when mixed oil and gas are involved, and increases with the increase of rotating speed. ${ }^{17,46}$ Based upon the method for calculating the working resistance of turbine rotor, the windage loss of double helical gear trains is given in Eq. (20).

$$
\left\{\begin{array}{l}
P_{W p}=2.82 \times 10^{-7}\left(1+2.3 \frac{b}{R_{p}}\right)\left(n_{p}\right)^{2.8} \\
R_{p}^{4.6}(0.028 v+0.019)^{0.2} \\
P_{W g}=2.82 \times 10^{-7}\left(1+2.3 \frac{b}{R_{g}}\right)\left(\frac{n_{p}}{m_{g}}\right)^{2.8} \\
R_{g}^{4.6}(0.028 v+0.019)^{0.2}
\end{array}\right.
$$

where $P_{W p}, P_{W g}$ indicate the windage loss in left and right helical gear pairs; $b$ denotes the total tooth width including the width of cutter groove; $n_{p}$ represents the rotational speed of active gear; $m_{g}$ represents the total mass of passive gear.

\subsection{Dynamic Transmission Efficiency of DHGT}

DTEF of double helical gear trains is subsequently established after a comprehensive analysis of friction power loss between contacting teeth pairs, friction loss of rolling bearings and windage loss.

$$
\eta_{M}(t)=1-\frac{P_{f}\left\{F_{d}(t)\right\}+P_{B}(t)+P_{W p}+P_{W g}}{P_{0}} ;
$$

where $\eta_{M}$ is the time-varying DTEF of double helical gear trains; $P_{0}$ is the input power of double helical gear trains.

The basic parameters of double helical gear trains are listed in Tab. 3.

According to the analysis of DTEF, an example is given in Fig. 6 to demonstrate the difference between DTEF and the static transmission efficiency (STEF).

It can be seen that the STEF varies with the tooth meshing position, and the average STEF is $98.01 \%$; however, the
Table 3. Key parameters of double helical gear trains

\begin{tabular}{|c|c|c|}
\hline Parameter name & Driving gear & Driven gear \\
\hline Module $[\mathrm{mm}]$ & 5 & 5 \\
\hline Pressure angle $\left[{ }^{\circ}\right]$ & 20 & 20 \\
\hline Helix angle ${ }^{\circ}{ }^{\circ}$ & 26.1 & -26.1 \\
\hline Face contact ratios & 1.67 & 1.67 \\
\hline Profile contact ratios & 1.21 & 1.21 \\
\hline External torque $[\mathrm{N} \cdot \mathrm{m}]$ & - & 828 \\
\hline Density $\left[\mathrm{g} \cdot \mathrm{cm}^{3}{ }^{]}\right.$ & 7.80 & 7.80 \\
\hline Number of teeth & 17 & 44 \\
\hline Tooth width $[\mathrm{mm}]$ & 55 & 55 \\
\hline Input speed $[\mathrm{r} / \mathrm{min}]$ & 2000 & - \\
\hline Bearing designation & NSK-NU211EW & NSK-HR32914J \\
\hline Width of groove $[\mathrm{mm}]$ & 50 & 50 \\
\hline Center distance error $[\mu \mathrm{m}]$ & 5 & 5 \\
\hline Axis angle error $\left[{ }^{\circ}\right]$ & 0.05 & 0.05 \\
\hline
\end{tabular}

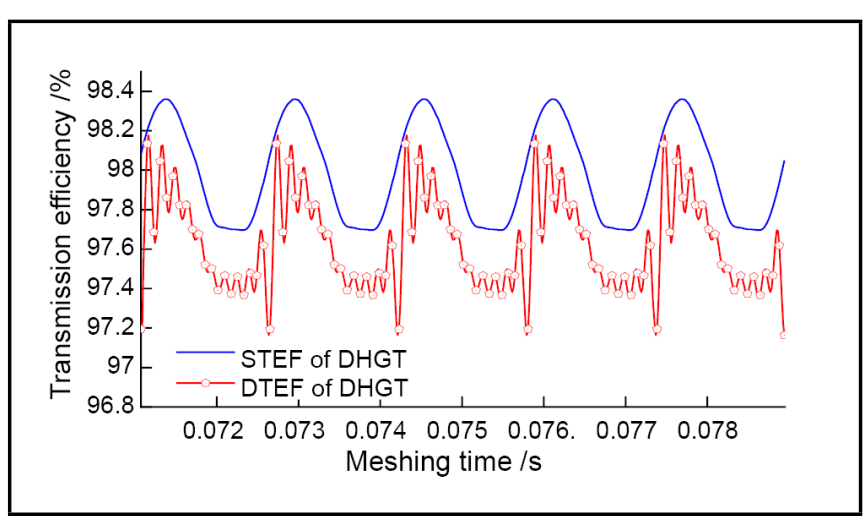

Figure 6. Comparison of STEF and DTEF.

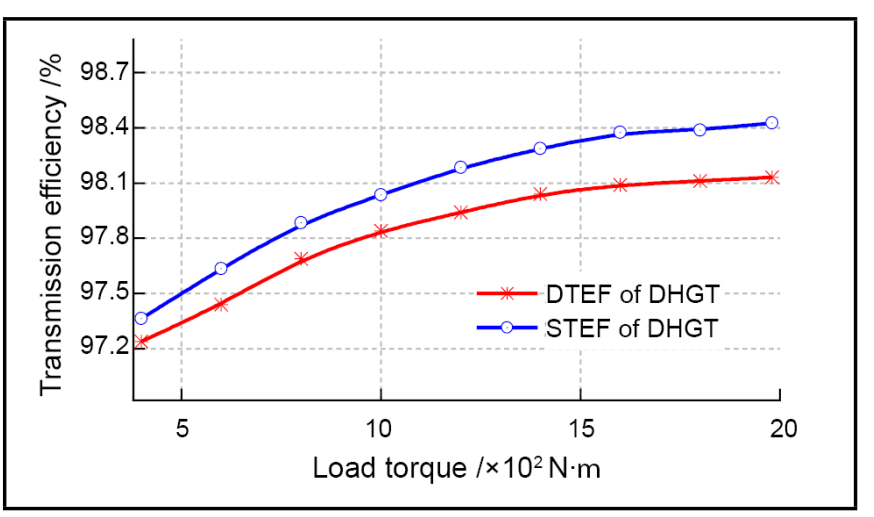

Figure 7. Comparison of TEF under different loads (2000 r/min).

DTEF in the case of dynamic load features an obvious fluctuation, and the average DTEF is $97.74 \%$. It also indicates that the DTEF with vibration force is lower than STEF, this is consistent with the conclusion that the transmission quality is reduced, and total power loss is increased due to the tooth surface error, stiffness fluctuation, meshing impact and other excitations. Therefore, it is necessary to evaluate the system efficiency by DTEF in practical application.

Further analysis of the differences between DTEF and STEF from the perspective of loads and rotating speeds are shown in Fig. 7 and Fig. 8.

As shown in Fig. 7, under the condition of constant input speed, both of the two efficiencies increase slightly with the increase of external loads at first, when the external load exceeds a certain value $(1800 \mathrm{~N} \cdot \mathrm{m})$, the efficiencies tend to be 


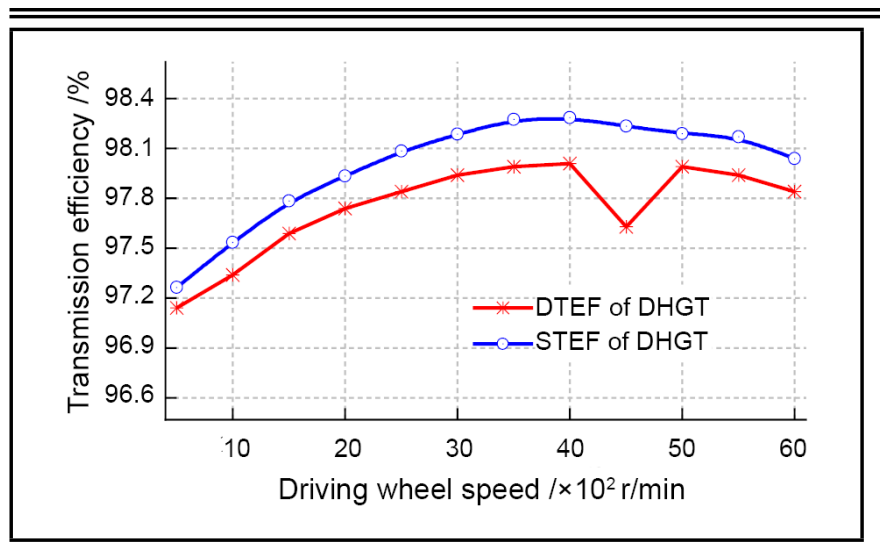

Figure 8. Comparison of TEF under different speeds (828 N·m).

stable. As shown in Fig. 8, the STEF and DTEF increase with the increase of input speeds, since the lubrication film is easier to form at higher input speed; however, the DTEF decreases rapidly when the input speed reaches the first-order resonance speed (4700 r/min), since the resonant dynamic load is obviously larger than the static load. The result shows that the DTEF is of great significance for the design of high-speed gear.

\subsection{Teeth Modification Optimization of DTEF}

The 3-D modification of double helical gear trains is an efficient technology in which the profile and lead modifications are employed to elevate the comprehensive contact quality of the tooth surface, especially the reduction of vibration load and friction coefficient. The 3-D modification surface of a double helical gear is shown in Fig. 9.

To obtain the optimal design parameters of teeth shape for 3-D modification, if the average DTEF is set as the objective of optimization, then the optimization function of the tooth surface modification for a double helical gear pair is established, as shown in Eq. (22)-(24).

$$
\begin{gathered}
f_{C}\left(y_{i j}\right)=\min \left(\frac{1}{\eta_{A V G}}\right) \\
\begin{cases}\left|y_{1 L}-y_{3 L}\right| \leq Q_{y 0}, & \left|y_{2 L}-y_{4 L}\right| \leq l_{y 0} \\
Q_{y \min } \leq y_{1 R}, y_{3 R} \leq Q_{y \max }, & l_{y \min } \leq y_{2 R}, y_{4 R} \leq l_{y \max } \\
\left|y_{5 L}-y_{7 L}\right| \leq Q_{z 0}, & \left|y_{6 L}-y_{8 L}\right| \leq l_{z 0} \\
Q_{z \min } \leq y_{5 L}, y_{7 L} \leq Q_{z \max }, & l_{z \min } \leq y_{6 L}, y_{8 L} \leq l_{z \max }\end{cases} \\
\begin{cases}\left|y_{1 R}-y_{3 R}\right| \leq Q_{y 0}, & \left|y_{2 R}-y_{4 R}\right| \leq l_{y 0} \\
Q_{y \min } \leq y_{1 R}, y_{3 R} \leq Q_{y \max }, & l_{y \min } \leq y_{2 R}, y_{4 R} \leq l_{y \max } \\
\left|y_{5 R}-y_{7 R}\right| \leq Q_{z 0}, & \left|y_{6 R}-y_{8 R}\right| \leq l_{z 0} \\
Q_{z \min } \leq y_{5 R}, y_{7 R} \leq Q_{z \max }, & l_{z \min } \leq y_{6 R}, y_{8 R} \leq l_{z \max }\end{cases}
\end{gathered}
$$

where $f_{C}$ denotes the multi-objective optimization function under a given working condition; $y_{i j}$ indicates the design parameters of left-helical and right-helical gear pairs; $\eta_{A V G}$ is the average transmission efficiency during one mesh cycle; $P_{0}$ is the input power of double helical gear trains; $l_{y m i n}$, $l_{y \max }, l_{z \min }, l_{z \max }, Q_{y \min }, Q_{y \max }, Q_{z \min }, Q_{z \max }$ denote the boundary values of each variable; $l_{y 0}, l_{z 0}, Q_{y 0}, Q_{z 0}$ represent the constant parameters for teeth profile modification. All the variables to be optimized are illustrated in Fig. 10.
The process of DTEF optimization includes the execution of LTAC program and calculation of DTEF equations, while altering the micro-modification parameters of the meshing tooth surface. The variables to be optimized are associated with the parameters for teeth modification, and the objective function of optimization is associated with the DTEF of double helical gear trains, there are no explicit formulas to describe these relationships. The optimization process based on a modified genetic algorithm and the theory of neural network is elaborated in Fig. $114^{48,49}$

The optimization results of modification parameters are finally obtained with the proposed method and are listed in Tab. 4. To demonstrate the effectiveness of parameter optimization and the advance of the optimal parameter, two other groups of parameters for teeth modifications have been configured, and corresponding calculations have been carried out as comparison, the additional parameters are listed in Tab. 5.

The comparison of DTEF before and after the teeth modification is given in Fig. 12. It is apparent that the fluctuation of DTEF is significantly reduced after the teeth modification; additionally, for the given condition (2000 r/min and $828 \mathrm{~N} \cdot \mathrm{m}$ ), the highest average DTEF $(98.39 \%)$ is realized by the gears modified with optimal parameters.

As shown in Fig. 13 and Fig. 14, for a more comprehensive analysis of the effects of shape modification on DTEF, the DTEF before and after the teeth modification with different external loads and speeds is calculated and compared.

As shown in Fig. 13, due to a lower actual contact ratio of double-helical gear pair when the external torque is below 630 $\mathrm{N} \cdot \mathrm{m}$, the average DTEF of double helical gear trains after 3D modification is lower than the standard tooth. However, the actual contact ratio of the gear pair with modified tooth increases when the external load increases, which accounts for the advantage of double helical gear in terms of transmission smoothness compared with the standard tooth. Therefore the performance of the double helical gear trains with 3-D modification is higher at this stage. In other words, the practical application will significantly benefit from the optimization process mentioned above and the 3-D modification for the gear teeth, in the case of a fixed external load. Similarly, Fig. 14 shows that the DTEF after the 3-D modification is significantly improved at different input speeds, owing to the decreased dynamic loads.

\section{EXPERIMENT AND THEORETICAL VERIFICATION}

The findings of this research cannot be practically implemented until the model is validated by experiments on the double helical gear-shaft-bearing system. The closed power flow experiment facilities have been successfully developed in recent years to overcome the drawback of the conventional test bench, such as high-power consumption and low energy efficiency. The closed power flow experiment facilities are distinguished by a closed-loop topology of energy flow. In other words, the energy consumed are partially collected and sent back in order to drive the test system, and in this way the energy conservation and the stability under overload conditions 


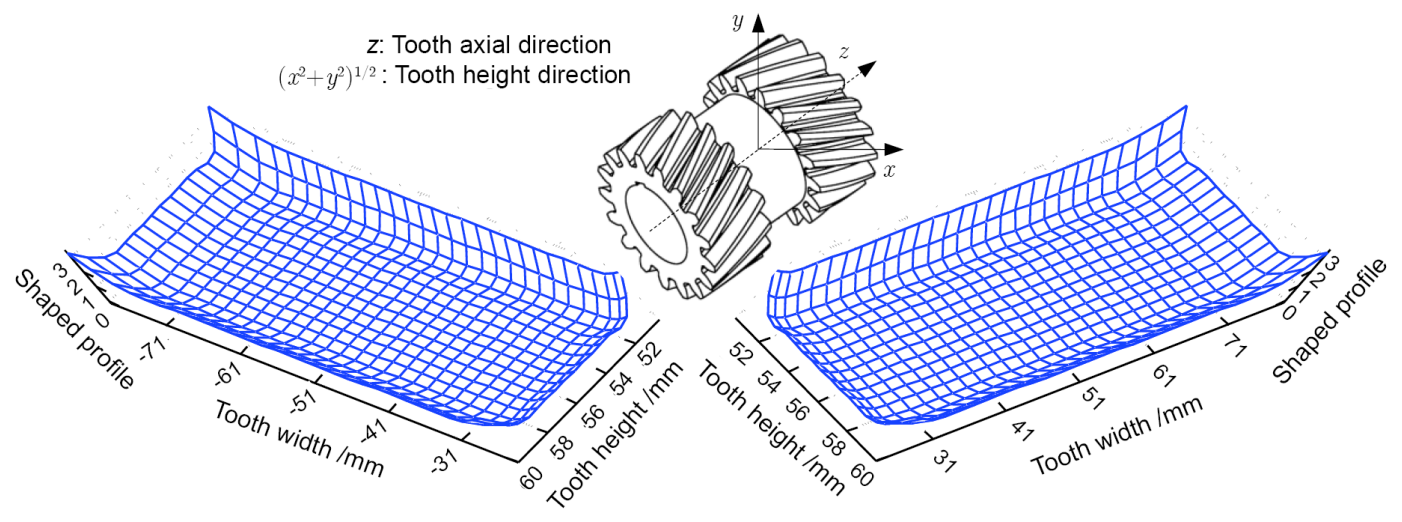

Figure 9. 3-D modification teeth shape of double helical gear.

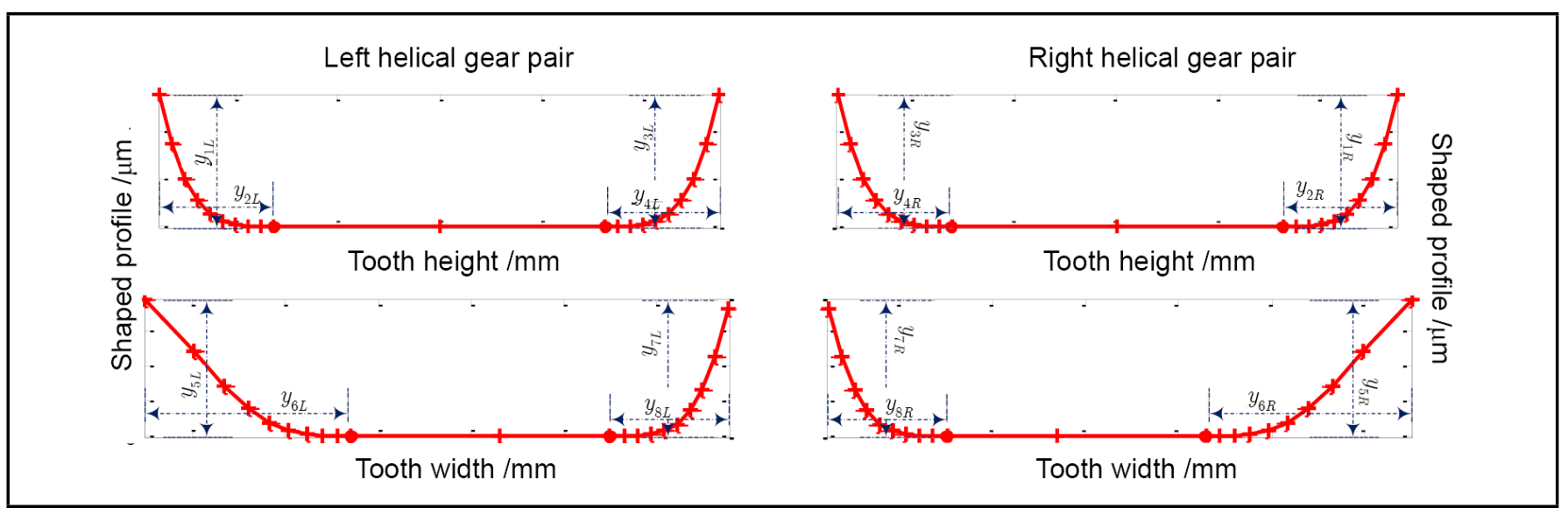

Figure 10. The schematic diagram of all variables to be optimized.

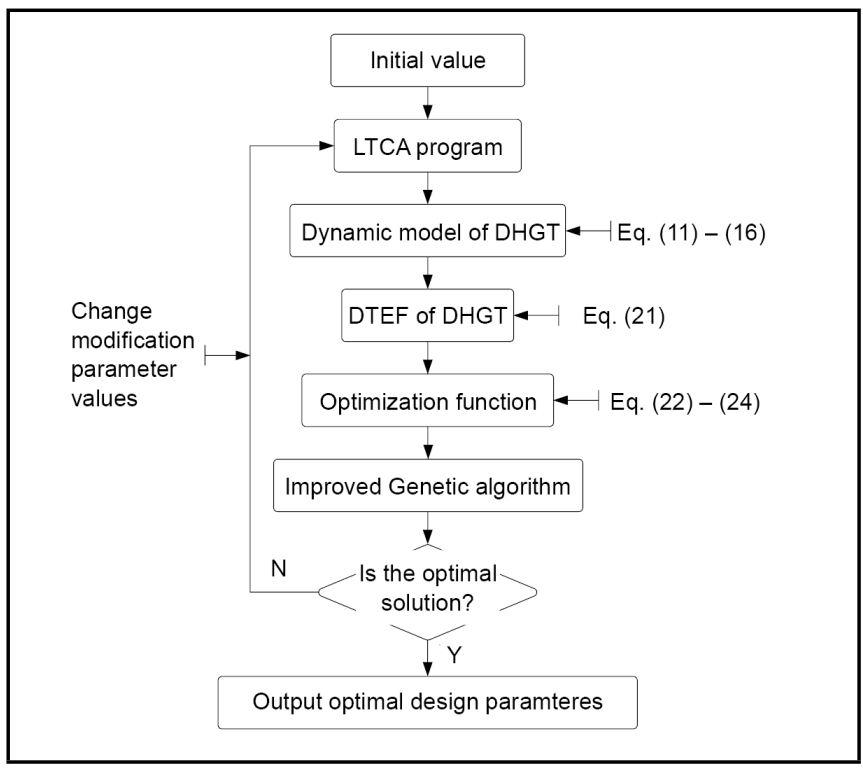

Figure 11. The optimization process of DTEF.

are strengthened. The configuration of closed power flow test bench employed in this research is illustrated in Fig. 15.

Torque encoder is used to measure the torques in input and output axes, and the Heidenhain optical encoders are used to measure the rotational speed accurately. The installation positions of torque encoder and the Heidenhain optical encoders are shown in Fig. 16. ${ }^{50-56}$ The modification of the tooth surface is achieved via grinding method, and the gear pairs to be tested

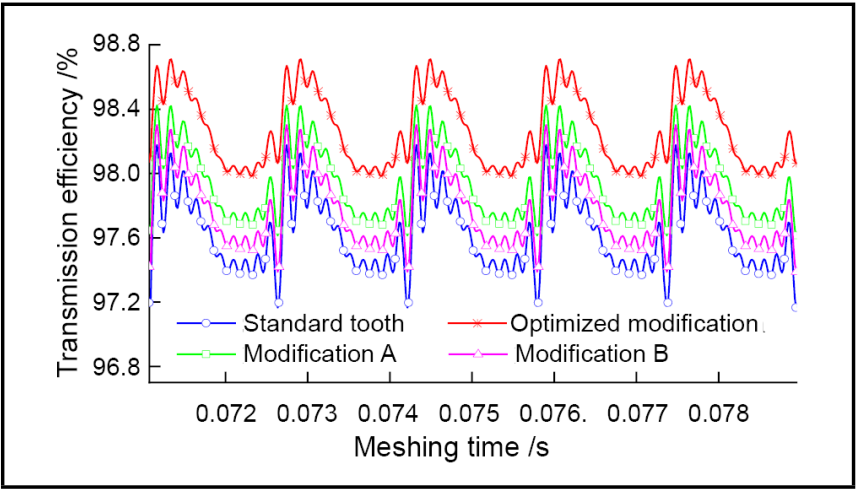

Figure 12. The comparison of DTEF before and after the teeth modification.

are machined by a CNC gear-grinding machine produced by Qinchuan Machine Tool Group Co., Ltd. We took some necessary measures for the gear pair and the rolling bearing system in experiments to ensure that the conditions for the experiments are as close as possible to the simulation environment. The techniques are applied primarily from the following three perspectives: (1) the tooth surface is manufactured with 4th precision grade to reduce the difference between ideal tooth surface and actual tooth surface; (2) a tolerable installation error is ensured during the assembly of test bench; and, (3) the quantity and temperature of lubricating oil is strictly selected for the gear pair and the rolling bearing. 
Table 4. The results of parameter optimization.

\begin{tabular}{|c|c|c|c|c|c|c|c|c||}
\hline Parameters/unit & $y_{1 L} / \mu \mathrm{m}$ & $y_{2 L} / \mathrm{mm}$ & $y_{3 L} / \mu \mathrm{m}$ & $y_{4 L} / \mathrm{mm}$ & $y_{5 L} / \mu \mathrm{m}$ & $y_{6 L} / \mathrm{mm}$ & $y_{7 L} / \mu \mathrm{m}$ & $y_{8 L} / \mathrm{mm}$ \\
\hline Value & 16 & 1.6 & 18 & 3.2 & 14 & 11.6 & 14 & 11.2 \\
\hline Parameters/unit & $y_{1 R} / \mu \mathrm{m}$ & $y_{2 R} / \mathrm{mm}$ & $y_{3 R} / \mu \mathrm{m}$ & $y_{4 R} / \mathrm{mm}$ & $y_{5 R} \mu \mathrm{m}$ & $y_{6 R} / \mathrm{mm}$ & $y_{7 R} / \mu \mathrm{m}$ & $y_{8 R} / \mathrm{mm}$ \\
\hline Value & 15 & 1.8 & 19 & 2.5 & 15 & 10.6 & 14 & 10.2 \\
\hline
\end{tabular}

Table 5. Modification parameters of comparison groups

\begin{tabular}{||c|c|c|c|c|c|c|c|c||}
\hline Parameters/unit & $y_{1 L} / \mu \mathrm{m}$ & $y_{2 L} / \mathrm{mm}$ & $y_{3 L} / \mu \mathrm{m}$ & $y_{4 L} / \mathrm{mm}$ & $y_{5 L} / \mu \mathrm{m}$ & $y_{6 L} / \mathrm{mm}$ & $y_{7 L} / \mu \mathrm{m}$ & $y_{8 L} / \mathrm{mm}$ \\
\hline Modification tooth A & 14 & 1.4 & 15 & 3.0 & 13 & 10.6 & 13 & 10.6 \\
\hline Modification tooth B & 17 & 1.8 & 19 & 3.5 & 16 & 12.1 & 16 & 11.9 \\
\hline Parameters/unit & $y_{1 R} / \mu \mathrm{m}$ & $y_{2 R} / \mathrm{mm}$ & $y_{3 R} / \mu \mathrm{m}$ & $y_{4 R} / \mathrm{mm}$ & $y_{5 R} \mu \mathrm{m}$ & $y_{6 R} / \mathrm{mm}$ & $y_{7 R} / \mu \mathrm{m}$ & $y_{8 R} / \mathrm{mm}$ \\
\hline Modification tooth A & 13 & 1.6 & 17 & 2.3 & 13 & 9.6 & 12 & 9.2 \\
\hline Modification tooth B & 16 & 1.9 & 21 & 2.8 & 17 & 11.2 & 16 & 11.2 \\
\hline
\end{tabular}

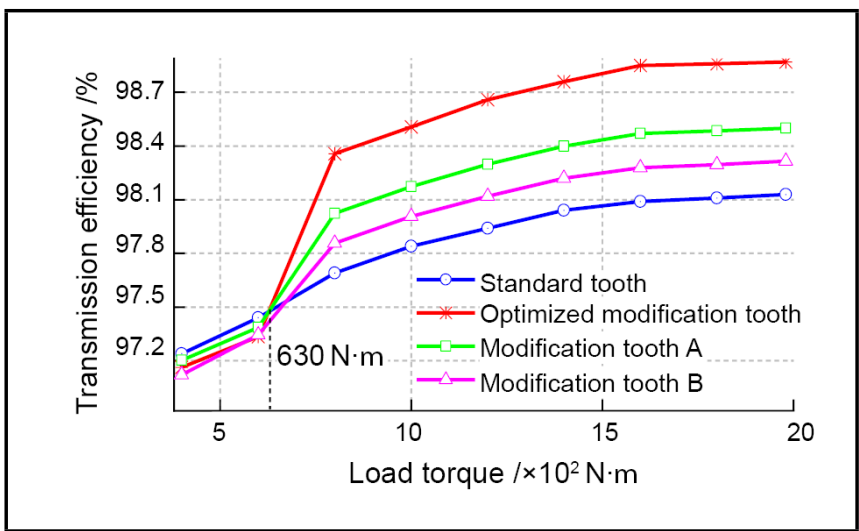

Figure 13. Comparison of DTEF with different loads (2000 r/min).

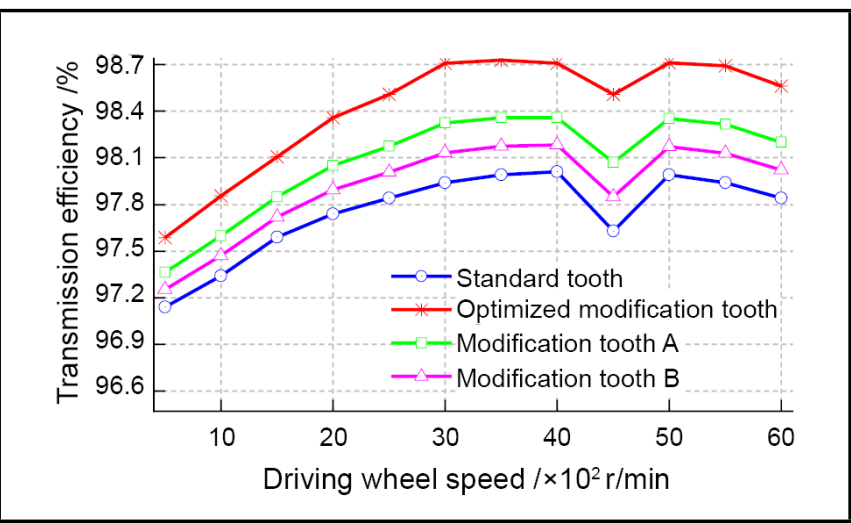

Figure 14. Comparison of DTEF with different speeds $(828 \mathrm{~N} \cdot \mathrm{m})$.

The experiment results of DTEF are calculated by Eq. (25).

$$
\eta_{T}(t)=\frac{T_{\text {out }}(t) \cdot n_{\text {out }}(t)}{T_{\text {in }}(t) \cdot n_{\text {in }}(t)} ;
$$

where $\eta_{T}$ denotes the experiment results of DTEF; $T_{i n}(t)$, $T_{\text {out }}(t)$ represent the input torque and output torque of double helical gear trains; $n_{\text {in }}, n_{\text {out }}$ indicate the input speed and the output speed of the double helical gear trains.

As shown in Fig. 18, the fluctuation tendency of timevarying DTEF measured in the experiment is consistent with the results of theoretical calculation. The average time-varying DTEF before and after teeth modification are $97.48 \%$ and $98.06 \%$, respectively. Therefore, the modification of the tooth surface proves efficient in improving DTEF under the given operating condition. In addition, due to the inevitable factors that influence the experiment accuracy, e.g., the manufacture and installation errors, the experimental results are slightly

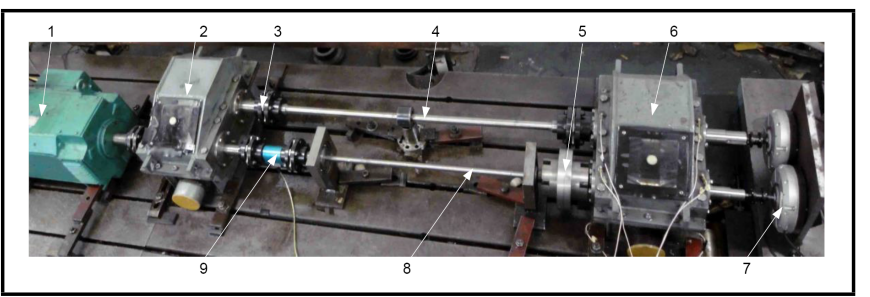

Figure 15. Test rig for double helical gear trains(1.DC motor; 2.the master gearbox; 3.coupling; 4.low-speed torsion shaft; 5.Simple loader; 6.test box; 7.Heidenhain optical encoders; 8.high-speed torsion shaft; 9.rotating speed and torque sensor)

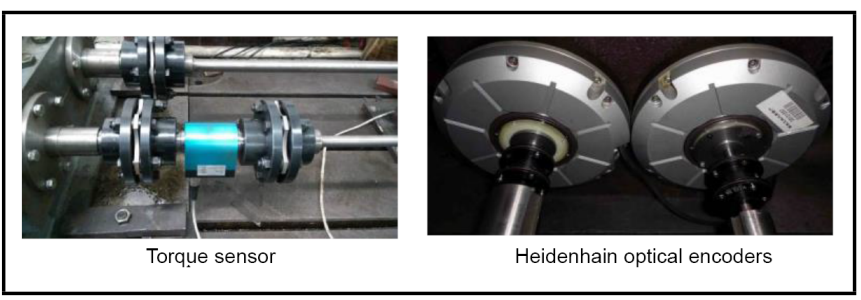

Figure 16. The installation positions of torque encoder and the Heidenhain optical encoders.

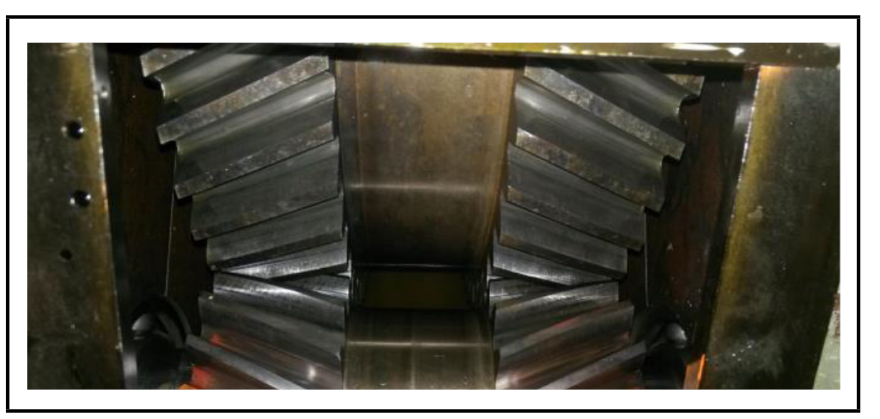

Figure 17. The meshing double helical gear pair.

lower than the ideal value.

The experimental data are measured 5 times to show the data range of experiments in Tab. 6 and Tab. 7, and the average values are used as the final results in Fig. 19 and Fig. 20.

The comparisons of DTEF from simulation and experiment with different loads and speeds are shown in Fig. 19 and Fig. 20, the differences between the results of theoretical calculation and experiment for this two conditions are basically the same. The engineering practices indicate the feasibility of this method for calculation of the DTEF. 
F. Wang, et al.: EFFECT OF TOOTH SURFACE MODIFICATION ON DYNAMIC TRANSMISSION EFFICIENCY OF DOUBLE HELICAL GEAR...

Table 6. The mean value of each measurement result of DTEF (2000 r/min).

\begin{tabular}{|c|c|c|c|c|c|c|c|c|c|c|}
\hline & \multirow{2}{*}{$\begin{array}{c}\text { Number of } \\
\text { measurements }\end{array}$} & \multicolumn{9}{|c|}{ Load torque /N·m } \\
\hline & & 428 & 628 & 828 & 1028 & 1228 & 1428 & 1628 & 1828 & 2028 \\
\hline \multirow{6}{*}{ Transmission efficiency $/ \%$ (Standard tooth) } & $1 \mathrm{st}$ & 97.16 & 97.25 & 97.53 & 97.57 & 97.77 & 97.87 & 98.00 & 98.03 & 98.06 \\
\hline & 2ed & 97.21 & 97.31 & 97.58 & 97.56 & 97.79 & 97.93 & 98.01 & 98.03 & 98.08 \\
\hline & $3 \mathrm{rd}$ & 97.15 & 97.26 & 97.53 & 97.54 & 97.79 & 97.88 & 98.03 & 98.06 & 98.03 \\
\hline & 4th & 97.21 & 97.32 & 97.52 & 97.61 & 97.80 & 97.90 & 97.99 & 98.08 & 98.10 \\
\hline & 5 th & 96.98 & 97.07 & 97.29 & 97.41 & 97.56 & 97.63 & 97.91 & 97.85 & 97.89 \\
\hline & Mean value & 97.14 & 97.24 & 97.48 & 97.54 & 97.74 & 97.84 & 97.99 & 98.01 & 98.03 \\
\hline \multirow{6}{*}{ Transmission efficiency $/ \%$ (Modification tooth) } & $1 \mathrm{st}$ & 97.00 & 97.17 & 98.09 & 98.35 & 98.46 & 98.60 & 98.68 & 98.77 & 98.78 \\
\hline & 2ed & 97.01 & 97.21 & 98.11 & 98.36 & 98.47 & 98.64 & 98.69 & 98.80 & 98.78 \\
\hline & 3rd & 97.03 & 97.17 & 98.11 & 98.33 & 98.47 & 98.56 & 98.68 & 98.76 & 98.79 \\
\hline & 4th & 97.01 & 97.14 & 98.12 & 98.39 & 98.50 & 98.60 & 98.71 & 98.86 & 98.79 \\
\hline & 5th & 96.95 & 96.96 & 97.86 & 98.12 & 98.39 & 98.40 & 98.49 & 98.60 & 98.71 \\
\hline & Mean value & 97.00 & 97.13 & 98.06 & 98.31 & 98.46 & 98.56 & 98.65 & 98.76 & 98.77 \\
\hline
\end{tabular}

Table 7. The mean value of each measurement result of DTEF $(828 \mathrm{~N} \cdot \mathrm{m})$.

\begin{tabular}{|c|c|c|c|c|c|c|c|c|c|c|c|c|c|}
\hline & \multirow{2}{*}{$\begin{array}{c}\text { Number of } \\
\text { measurements }\end{array}$} & \multicolumn{12}{|c|}{ Wheel speed /r/min } \\
\hline & & 500 & 1000 & 1500 & 2000 & 2500 & 3000 & 3500 & 4000 & 4500 & 5000 & 5500 & 6000 \\
\hline \multirow{5}{*}{$\begin{array}{c}\text { Transmission efficiency / } \\
\% \text { (Standard tooth) }\end{array}$} & $1 \mathrm{st}$ & 97.08 & 97.17 & 97.43 & 97.52 & 97.67 & 97.82 & 97.82 & 97.95 & 97.46 & 97.85 & 97.87 & 97.75 \\
\hline & 2ed & 97.14 & 97.16 & 97.47 & 97.50 & 97.69 & 97.82 & 97.84 & 98.01 & 97.53 & 97.83 & 97.92 & 97.81 \\
\hline & 3rd & 97.07 & 97.15 & 97.43 & 97.50 & 97.65 & 97.85 & 97.80 & 97.91 & 97.46 & 97.83 & 97.88 & 97.74 \\
\hline & 4th & 97.13 & 97.18 & 97.42 & 97.50 & 97.69 & 97.87 & 97.85 & 98.00 & 97.48 & 97.90 & 97.90 & 97.80 \\
\hline & 5 th & 96.78 & 97.04 & 97.20 & 97.44 & 97.50 & 97.70 & 97.54 & 97.68 & 97.23 & 97.63 & 97.63 & 97.59 \\
\hline \multirow{6}{*}{$\begin{array}{c}\text { Transmission efficiency / } \\
\% \text { (Modification tooth) }\end{array}$} & $1 \mathrm{st}$ & 97.41 & 97.69 & 97.91 & 98.10 & 98.31 & 98.53 & 98.62 & 98.52 & 98.34 & 98.65 & 98.62 & 98.51 \\
\hline & 2ed & 97.45 & 97.71 & 97.92 & 98.08 & 98.37 & 98.53 & 98.63 & 98.56 & 98.35 & 98.70 & 98.65 & 98.47 \\
\hline & 3rd & 97.42 & 97.70 & 97.95 & 98.09 & 98.33 & 98.52 & 98.61 & 98.54 & 98.32 & 98.62 & 98.61 & 98.47 \\
\hline & 4th & 97.48 & 97.71 & 97.96 & 98.12 & 98.31 & 98.53 & 98.67 & 98.56 & 98.36 & 98.63 & 98.61 & 98.47 \\
\hline & 5 th & 97.13 & 97.45 & 97.81 & 97.91 & 98.22 & 98.44 & 98.52 & 98.36 & 98.18 & 98.45 & 98.46 & 98.38 \\
\hline & Mean value & 97.38 & 97.65 & 97.91 & 98.06 & 98.31 & 98.51 & 98.61 & 98.51 & 98.31 & 98.61 & 98.59 & 98.46 \\
\hline
\end{tabular}

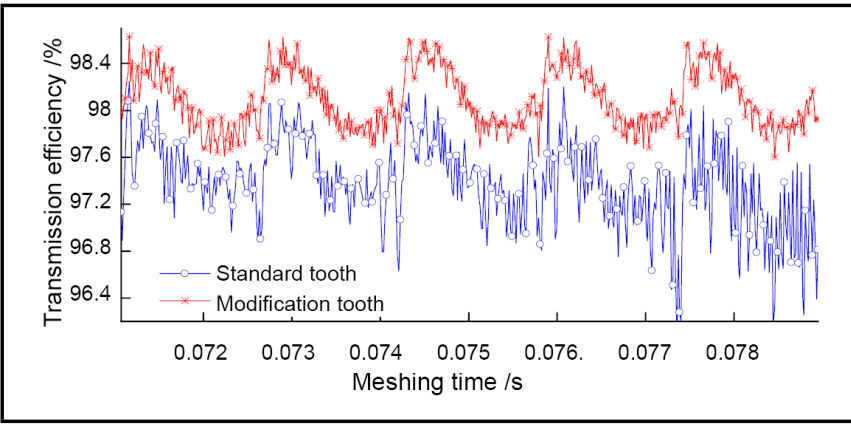

Figure 18. Experimental measurement for time-varying DTEF

\section{CONCLUSION}

A series of feasible methods for DTEF calculation and influence analysis for tooth surface modifications have been developed in this research. Based on the dynamics model and elastohydrodynamic lubrication model, a genetic algorithm was applied to the direct 3-D tooth surface modification for double helical gears; the proposed DTEF calculation method incorporating the real-time dynamic loads features high efficiency and accuracy. According to the simulation and experiments, the following conclusions concerning the DTEF can be drawn from this research:

(1) Compared with the conventional methods for calculation of static and quasi-dynamic transmission efficiencies, the new method for calculation of DTEF given due consideration of real-time dynamic loads performed better in terms of calculation speed and precision. The simulation showed that the fluctuation of DTEF was more obvious when the vibration force

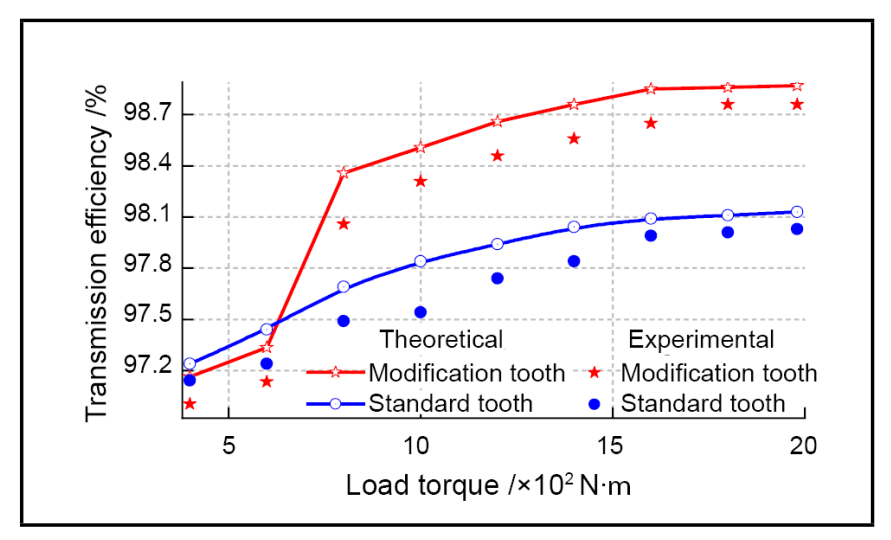

Figure 19. Comparison of theoretical and experimental results of DTEF with different torques (2000 r/min).

of tooth surface was considered, and the average DTEF was lower than STEF. It is worth noting that the DTEF at the resonant speed is significantly lower than STEF due to the rapid increase of dynamic load.

(2) The optimization of DTEF via 3-D modification technology was systematically elaborated in this paper, and according to the analysis of optimal solution data, the proposed modification model proved feasible and effective. Due to the decrease of dynamic loads, the DTEF after the 3-D modification was significantly higher than standard tooth at different input speeds. However, the effect of tooth surface modification was conditional, for instance, when the external torque was below $630 \mathrm{~N} \cdot \mathrm{m}$, the modified tooth was inferior to the standard tooth in terms of DTEF.

(3) Experimental data of DTEF were obtained by the torque 


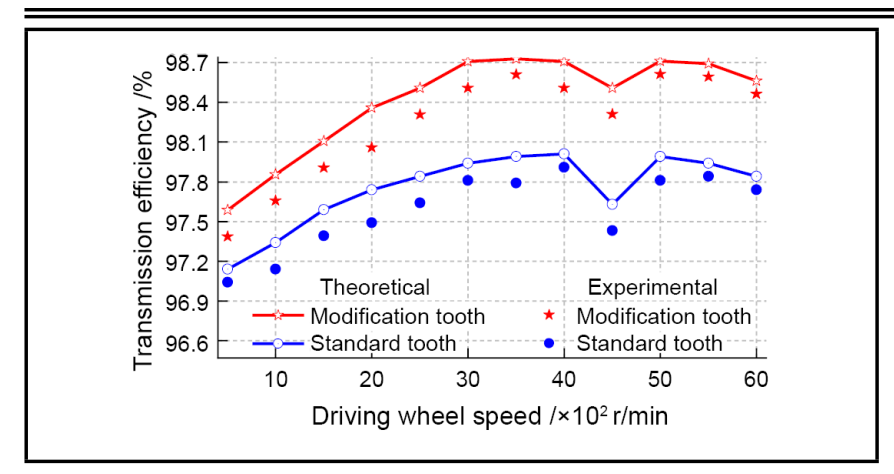

Figure 20. Comparison of theoretical and experimental results of DTEF with different speeds $(828 \mathrm{~N} \cdot \mathrm{m})$.

encoder (for torque measurements) and the Heidenhain optical encoders (for rotational speed measurements). The key characteristics of the DTEF in theory and experiment were highly consistent. The engineering practices support the feasibility of this method for the calculation of the DTEF.

\section{ACKNOWLEDGEMENT}

This work is financially supported by the Foundation of the State Key Laboratory of Mechanical Transmissions [SKLMTMSKFKT-202011], National Natural Science Foundation of China [No. 52172358], China Postdoctoral Science Foundation [No. 2020M671850], Six Talent Peaks Project in Jiangsu Province (CN) [No. JXQC-036], China Scholarship Council [No. 201908320221], the Primary Research and Development Plan of Jiangsu Province (CN) [No. BE2019010].

\section{REFERENCES}

1 Chen, S., Tang, J., Li, Y., \& Hu, Z. (2016). Rotordynamics analysis of a double-helical gear transmission system. Meccanica, 51(1), 1-18. https://dx.doi.org/10.1007/s11012015-0194-0

2 Zhu, X., Zhang, H., Cao, D., \& Fang, Z. (2015). Robust control of integrated motor-transmission powertrain system over controller area network for automotive applications. Mechanical Systems \& Signal Processing, 58-59, 15-28. https://dx.doi.org/10.1016/j.ymssp.2014.11.011

3 Kang, M. R., \& Kahraman, A. (2015). An experimental and theoretical study of the dynamic behavior of doublehelical gear sets. Journal of Sound \& Vibration, 350, 11-29. https://dx.doi.org/10.1016/j.jsv.2015.04.008

4 Liu, C., Qin, D., \& Liao, Y. (2014). Dynamic model of variable speed process for herringbone gears including friction calculated by variable friction coefficient. Journal of Mechanical Design, 136(4), 041006. https://dx.doi.org/10.1115/1.4026572

5 Sondkar, P. B. (2012). Dynamic modelling of double-helical planetary gear sets. Dissertations \& Theses Gradworks, The Ohio State University. https://dx.doi.org/10.1533/9781782421955.889
6 Yin, C., Zhang, J., Wang, S. (2017) Influence of damper indicator diagram area on vehicle ride comfort. Journal of Jiangsu University (Natural Science Edition), 38(6), 645-651. https://dx.doi.org/10.3969/j.issn.16717775.2017.06.005

7 Rao, K. B., Reddy, D. M. (2021). Fault detection in rotor system by discrete wavelet neural network algorithm. Journal of Vibration and Control, 24(7), 107754632110307. https://dx.doi.org/10.1177/10775463211030754

8 Zhang, N., Zhou, C., Gao, Z. (2017) Torque distribution strategy of PHEV based on FCMAC neural network. Journal of Jiangsu University (Natural Science Edition), 38(6), 652-657. https://dx.doi.org/10.3969/j.issn.16717775.2017.06.006

9 Rao, K. B., Reddy, D. M. (2021). Dynamic analysis of multi disc rotating stepped shaft through signal processing. International Conference on Design, Automation and Control (ICDAC2020) IOP Conf. Series: Materials Science and Engineering. https://dx.doi.org/10.1088/1757899X/1123/1/012016

10 Kolivand, M., Li, S., \& Kahraman, A. (2010). Prediction of mechanical gear mesh efficiency of hypoid gear pairs. Mechanism \& Machine Theory, 45(11), 1568-1582. https://dx.doi.org/10.1016/j.mechmachtheory.2010.06.015

11 Li, S., \& Kahraman, A. (2010). A transient mixed elastohydrodynamic lubrication model for spur gear pairs. Journal of Tribology, 132(1), 011501.https://dx.doi.org/doi.org/10.1115/1.4000270

12 Li, S., \& Kahraman, A. (2013). A tribo-dynamic model of a spur gear pair. Journal of Sound \& Vibration, 332(20), 4963-4978.https://dx.doi.org/10.1016/j.jsv.2013.04.022

13 Concli, F. (2013). Analysis of power losses in an industrial planetary speed reducer: measurements and computational fluid dynamics calculations. ARCHIVE Proceedings of the Institution of Mechanical Engineers Part J Journal of Engineering Tribology 1994-1996 (vols 208-210), 44(2), 1-3. https://dx.doi.org/10.1177/1350650113496980

14 Liu, H., Jurkschat, T., Lohner, T., \& Stahl, K. (2017). Determination of oil distribution and churning power loss of gearboxes by finite volume cfd method. Tribology International, 109, 346354.https://dx.doi.org/10.1016/j.triboint.2016.12.042

15 Al-Shibl, Simmons, Eastwick, \& C., N. (2007). Modelling windage power loss from an enclosed spur gear. Proceedings of the Institution of Mechanical Engineers Part A Journal of Power \& Energy, 221(221), 331341.https://dx.doi.org/10.1243/09576509jpe344

16 Concli, F. (2016). Gear lubrication and efficiency predictions: a new mesh-handling algorithm to reduce 
the CFD simulation time. International Caeconference. https://dx.doi.org/10.1155/2016/2957151

17 Chen, C., \& Liang, T. T. (2011). Theoretic study of efficiency of two-dofs of epicyclic gear transmission via virtual power. Journal of Mechanical Design, 133(3), 031007. https://dx.doi.org/10.1115/1.4003568

18 Wang, B., Lu, Z. J., Chen, X. B., Wang, P., Luo, W., \& Xu, H. (2015). Modelling and analysis of the dynamic efficiency of manual transmission/reducer. International Journal of Automotive Technology, 16(3), 417-426. https://dx.doi.org/10.1007/s12239-015-0043-0

19 Chou, C. (2007). A model for the prediction of churning losses in geared transmissions-preliminary results. Journal of Mechanical Design, 129(1), 128-133. https://dx.doi.org/10.1115/1.2403727

20 Yu, J., Wu, C. Y., Hu, Y. H. (2016) Characteristic analysis of a new compound HMCVT. Journal of Jiangsu University (Natural Science Edition), 37(5), 507-511. hhttps://dx.doi.org/10.3969/j.issn.1671-7775.2016.05.003

21 Petrescu, R. V., Petrescu, F. I., \& Popescu, N. (2006). Save energy and diminish the pollutions by increasing the efficiency of gears. In Conferinţa Naţională "mediu-06”, Craiova, Romania. https://dx.doi.org/10.1007/978-3-6422491-9_34

22 Tůma, J. (2014). Vehicle gearbox noise and vibration: measurement, signal analysis, signal processing and noise reduction measures. Gastroenterology, 144(2), 381-391. https://dx.doi.org/10.1002/9781118797563

23 Diez-Ibarbia, A., Fernandez-Del-Rincon, A., De-Juan, A., Iglesias, M., Garcia, P., \& Viadero, F. (2017). Frictional power losses on spur gears with tip reliefs. the load sharing role. Mechanism \& Machine Theory, 112, 240-254. https://dx.doi.org/10.1016/j.mechmachtheory.2017.02.012

24 Diez-Ibarbia, A., Rincon, A. F. D., Iglesias, M., De-Juan, A., Garcia, P., \& Viadero, F. (2016). Efficiency analysis of spur gears with a shifting profile. Meccanica, 51(3), 1-17. https://dx.doi.org/10.1007/s11012-015-0209-x

25 Concli, F. (2015). Increasing efficiency of precision planetary gearboxes. GearForum. https://dx.doi.org/10.1097/00006199-198407000-00013

26 Terauchi, Y., \& Nadano, H. (1982). Effect of tooth profile modification on the scoring resistance of spur gears. Wear, 80(1), 27-41. https://dx.doi.org/10.1016/00431648(82)90085-0

27 Imrek, H., \& Sure, B. (2013). Effect of tooth width modification on wear in brass spur gears. Journal of the Balkan Tribological Association, 19(4), 547-557. https://dx.doi.org/10.1016/j.wear.2006.06.004
28 Qian, M. B., Yu, G. H., Zhang, X. F., Chu, B. B. (2016) Design method and fatigue strength analysis of eccentricnoncircular gear transmission mechanism. Journal of Jiangsu University (Natural Science Edition), 37(1), 44-48. https://dx.doi.org/10.3969/j.issn.1671-7775.2016.01.009

29 González-Cruz, C. A., Jáuregui-Correa, J. C., DomínguezGonzález, A., \& Lozano-Guzmán, A. (2016). Effect of the coupling strength on the nonlinear synchronization of a single-stage gear transmission. Nonlinear Dynamics, 1-18. https://dx.doi.org/10.1007/s11071-016-2673-9

30 Qian, M. B., Yu, G. H., Zhang, X. F. (2016) Design method and fatigue strength analysis of eccentricnoncircular gear transmission mechanism. Journal of Jiangsu University (Natural Science Edition), 37(1), 44-48. https://dx.doi.org/10.3969/j.issn.1671-7775.2016.01.009

31 Fernandes, C. M. C. G., Marques, P. M. T., Martins, R. C., \& Seabra, J. H. O. (2015). Gearbox power loss. part II: friction losses in gears. Tribology International, 88, 309-316. https://dx.doi.org/10.1016/j.triboint.2014.12.004

32 Cai, Y., Gao, L., Chen, L. (2017) Lane detection method based on clustering algorithm. Journal of Jiangsu University (Natural Science Edition), 38(6), 621-625. https://dx.doi.org/10.3969/j.issn.1671-7775.2017.06.001

33 Li, H., Wang, L., Chen, G. (2017) Dynamic meshing characteristics analysis of differential gears based on finite element. Journal of Jiangsu University (Natural Science Edition), 38(6): 626-631. https://dx.doi.org/10.3969/j.issn.1671-7775.2017.06.002

34 Sun, P., Han, S., Li, X. J. (2016) Shear property of ultrathin wearing course asphalt mixture. Journal of Jiangsu University (Natural Science Edition), 37(5), 610-615. https://dx.doi.org/10.3969/j.issn.1671-7775.2016.05.019

35 Dong Zhu, \& YuanZhong Hu. (2001). A computer program package for the prediction of ehl and mixed lubrication characteristics, friction, subsurface stresses and flash temperatures based on measured 3-d surface roughness. Tribology Transactions, 44(3), 383-390. https://dx.doi.org/10.1080/10402000108982471

$36 \mathrm{Xu}, \mathrm{H}$. (2007). A novel formula for instantaneous coefficients of sliding friction in gearing. Sae Technical Papers, 68(3), 513-521. https://dx.doi.org/10.4271/2007-01-4207

37 Feng, Z., Wang, S., Lim, T. C., \& Peng, T. (2011). Enhanced friction model for high-speed right-angle gear dynamics. Journal of Mechanical Science \& Technology, 25(11), 2741-2753. https://dx.doi.org/10.1007/s12206-0110803-3

38 Shifeng $\mathrm{Wu}$, \& H. S. Cheng. (1991). A friction model of partial-ehl contacts and its application to power loss in spur gears. Tribology Transactions, 34(3), 398-407. https://dx.doi.org/10.1080/10402009108982050 
39 Sun, X., Chen, L., Jiang, H., \& Yang, Z. (2016). High-performance control for a bearingless permanentmagnet synchronous motor using neural network inverse scheme plus internal model controllers. IEEE Transactions on Industrial Electronics, 63(6), 3479-3488. https://dx.doi.org/10.1109/tie.2016.2530040

40 Sun, X., Shi, Z., Chen, L., \& Yang, Z. (2016). Internal model control for a bearingless permanent magnet synchronous motor based on inverse system method. IEEE Transactions on Energy Conversion, 31(4), 1539-1548. https://dx.doi.org/10.1109/ipemc.2009.5157695

${ }^{41}$ Sun, X., Su, B., Chen, L., Yang, Z., Xu, X., \& Shi, Z. (2017). Precise control of a four degreeof-freedom permanent magnet biased active magnetic bearing system in a magnetically suspended directdriven spindle using neural network inverse scheme. Mechanical Systems \& Signal Processing, 88, 36-48. https://dx.doi.org/10.1016/j.ymssp.2016.11.022

42 Diez-Ibarbia, A., Fernandez-Del-Rincon, A., Garcia, P., De-Juan, A., Iglesias, M., \& Viadero, F. (2017). Assessment of load dependent friction coefficients and their influence on spur gears efficiency. Meccanica, 3, 1-21. https://dx.doi.org/10.1007/s11012-017-0736-8

43 Wang, F. (2014) Dynamic characteristics research and experimental study on herringbone gear drive system. Northwestern Polytechnical University. https://dx.doi.org/10.1638523.2016.02.005

44 Amarnath, M., \& Sujatha, C. (2015). Surface contact fatigue failure assessment in spur gears using lubricant film thickness and vibration signal analysis. Tribology Transactions, $\mathbf{5 8 ( 2 ) , \quad 3 2 7 - 3 3 6 .}$ https://dx.doi.org/10.1080/10402004.2014.971993

45 Anderson N E, Loewenthal S H. Spur gear system efficiency at part and full load[M]. National Aeronautics and Space Administration, Scientific and Technical Information Office, 1980. https://dx.doi.org/10.1036/10978542.pr000010

46 Jiang, H. B., Li, A. X., Ma, S. D. (2017) Design and performance analysis of airflow energy recovery device of electric vehicle. Journal of Jiangsu University (Natural Science Edition), 38(2),125-132. https://dx.doi.org/10.3969/j.issn.1671-7775.2017.02.001

47 Concli, F., \& Gorla, C. (2016). Numerical modeling of the power losses in geared transmissions: windage, churning and cavitation simulations with a new integrated approach that drastically reduces the computational effort. Tribology International, 103, 58-68. https://dx.doi.org/10.1016/j.triboint.2016.06.046
${ }^{48}$ Ren, W. L., Hao, Z. H.,Wang, Y.,Xu, J. (2017). Application of improved particle swarm algorithm in 3D design of hydrofoil. Journal of Jiangsu University (Natural Science Edition), 38(2), 168-172. https://dx.doi.org/10.3969/j.issn.1671-7775.2017.02.008

49 Morris, G. M., Goodsell, D. S., Halliday, R. S., Huey, R., Hart, W. E., \& Belew, R. K., et al. (2015). Automated docking using a lamarckian genetic algorithm and an empirical binding free energy function. Journal of Computational Chemistry, 19(14), 1639-1662.https://dx.doi.org/10.1002/(sici)1096987x(19981115)19:14\%3C1639::aid-jcc10\%3E3.0.co;2-b

50 Wang, F., Xu, X., Fang, Z., \& Chen, L. (2017). Design and analysis of herringbone gear with sixth-order transmission error based on meshing vibration optimization. Advances in Mechanical Engineering,9,6(2017-6-01), 9(6), 168781401770435. https://dx.doi.org/10.1177/1687814017704359

${ }^{51}$ Sun, X., Yuan, C., Cai, Y., Wang, S., \& Chen, L. (2017). Model predictive control of an air suspension system with damping multi-mode switching damper based on hybrid model. Mechanical Systems \& Signal Processing, 94, 94110. https://dx.doi.org/10.21595/jve.2016.17284

52 Wang, G., Sun, L., Li, X. (2017). Design of postharvest in field grading system for navel orange based on machine vision. Journal of Jiangsu University (Natural Science Edition), 38(6), 672-676. https://dx.doi.org/10.3969/j.issn.1671-7775.2017.06.009

${ }^{53}$ Sun, X., Chen, L., Yang, Z., \& Zhu, H. (2013). Speedsensorless vector control of a bearingless induction motor with artificial neural network inverse speed observer. IEEE/ASME Transactions on Mechatronics, 18(4), 13571366. https://dx.doi.org/10.1109/tmech.2012.2202123

54 Wang, F., Xu, X., Fang, Z., \& Chen, L. (2017). Study of the influence mechanism of pitch deviation on cylindrical helical gear meshing stiffness and vibration noise. Advances in Mechanical Engineering, 9(9), 168781401772058. https://dx.doi.org/10.1177/1687814017720586

55 Zhang, Y., Li, Z., Liu, X. (2017). Experiment on tension compression ratio of steel fiber reinforced concrete. Journal of Jiangsu University (Natural Science Edition), 38(6), 719-723. https://dx.doi.org/10.3969/j.issn.16717775.2017.06.017

56 Sun, X., Chen, L., \& Yang, Z. (2013). Overview of bearingless permanent-magnet synchronous motors. IEEE Transactions on Industrial Electronics, 60(12), 5528-5538. https://dx.doi.org/10.1109/tie.2012.2232253 